\title{
Identification and characterisation of Escherichia coli strains of 0157 and non-0157 serogroups containing three distinct Shiga toxin genes
}

\author{
SABINE FÜRST, JÜRGEN SCHEEF, MARTINA BIELASZEWSKA*, HOLGER RÜSSMANN†, \\ HERBERT SCHMIDT and HELGE KARCH
}

Institut für Hygiene und Mikrobiologie der Universität Würzburg, Josef-Schneider-Str. 2, 97080 Würzburg, Germany, *Institute of Medical Microbiology, 2nd Medical Faculty, Charles University, 15006 Prague, Czech Republic and †Max von Pettenkofer-Institut für Hygiene und Mikrobiologie der Ludwig Maximilians Universität München, Pettenkoferstraße 9a, 80336 München, Germany

\begin{abstract}
Three Shiga toxin (Stx)-producing Escherichia coli (STEC) strains from patients with diarrhoea were identified, each of which contained three distinct stx genes (stx $x_{1}$, stx $x_{2}$ and $\left.s t x_{2 c}\right)$. The strains belonged to the serotypes O52:H19, O75:H $\mathrm{H}^{-}$and $0157: \mathrm{H}^{-}$and harboured eae and EHEC-hly sequences. Colony-blot immunoassay was used to demonstrate that both major types of Stx were expressed. The association of stx genes with either phage or phage DNA was demonstrated in all three strains. Isolated phage DNA from all strains contained $s t x_{1}$ sequences, but stx $x_{2}$ sequences were found only in phage DNA of two of these strains. The presence of three distinct stx genes may enhance the virulence of STEC strains and should be monitored. The observations demonstrate not only the potential of $s t x$ genes to spread within different serotypes, but also their capacity to accumulate within a single strain.
\end{abstract}

\section{Introduction}

Shiga toxin (Stx)-producing Escherichia coli (STEC) strains are a widespread cause of haemorrhagic colitis and haemolytic uraemic syndrome (HUS). A large body of evidence supports the hypothesis that Stx plays a major role in the pathogenesis of HUS $[1,2]$.

The antigenically distinct toxins Stx 1 and Stx2 are produced alone or in combination by human STEC strains. In strains of E. coli $\mathrm{O} 157$ a variant of Stx2, termed Stx $2 c$, has been identified that is antigenically related to Stx2 [3]. Nucleotide sequence similarities between $s t x_{2}$ and $s t x_{2 c}$ were $99.6 \%$ and $94.8 \%$ in the Asubunit and B-subunit genes, respectively. Other members of the Stx2 family exist in non-O157 clinical STEC isolates. The genes for Stx 1 and Stx2 are encoded on separate temperate bacteriophages $[4,5]$ Phage induction may occur in response to agents causing damage to DNA, such as mitomycin $\mathrm{C}$, and under such conditions Stx expression is increased. The fact that stx genes are located in the genome of phages

Received 1 June 1999; revised version accepted 6 Sept. 1999.

Corresponding author: Dr H. Karch (e-mail: hkarch@, hygiene.uni-wuerzburg.de). may also facilitate their spread by transduction and, indeed, stx genes have been found in $>100$ serotypes of E. coli [6]. Furthermore, combinations of usually two stx genes have been reported in STEC O157:H7 as well as in non-O157 STEC of human origin [7, 8]. An earlier study identified six different patterns of stx genotypes including $s t x_{1}, s t x_{2}, s t x_{2 c}$, and combinations $s t x_{1} / s t x_{2}, \quad s t x_{1} / s t x_{2 c}$ and $s t x_{2} / s t x_{2 c}$ in STEC O157: $\mathrm{H} 7 / \mathrm{H}^{-}$strains isolated from patients with HUS [8]. Thomas et al. [7] found three stx genes (stx 1 $s_{2} x_{2} /$ stx $_{2 c}$ ) in $E$. coli $\mathrm{O} 157: \mathrm{H} 7 / \mathrm{H}^{-}$strains of human origin.

This study reports the finding of three STEC strains each harbouring the $s t x_{1}$, stx 2 and $s t x_{2 c}$ genes among 507 STEC isolates from patients with diarrhoea or HUS throughout Germany. It also presents evidence that the major Stx are expressed and that accessory virulence determinants and $s t x$-phages are present in these strains.

\section{Materials and methods}

Bacterial strains and phenotypic techniques

The STEC isolates were detected in stool samples of patients with diarrhoea and HUS between 1994 and 
1997 by PCR with primers GK3/GK4, LP43/LP44 and KS7/KS8 [9]. Serotyping was performed as described by Bockemühl et al. [10]. EHEC O157:H7 strain EDL933 (Stx1 and Stx2) [11], E. coli lysogen C600 (H19J) $\left(\mathrm{Stx}^{+}\right)$[4], E. coli lysogen C600 (933W) $\left(\mathrm{Stx}^{+}\right)$[12] and EHEC strain E32511 (Stx2c $\left.\mathrm{c}^{+}\right)$[3] were used as controls. E. coli strain DH5 $\alpha$ (GibcoBRL) was used as indicator strain in bacteriophage-induction experiments. The Vero cell cytotoxicity assay [9] and the colony blot immunoassay [8] were performed as described previously.

\section{PCR}

PCR reactions for detection of EHEC-specific sequences were performed with $10^{6}$ bacterial cells. Primers KS7 and KS8 were used to amplify the Bsubunit gene of Stx1 [9] and JS1 (5'-cat gaa gaa gat gtt tat ggc g- $\left.3^{\prime}\right)$ and JS2 (5'-ctc agt cat tat taa act gca c- $\left.3^{\prime}\right)$ to amplify the B-subunit gene of Stx2 and Stx2 variants. GK3 and GK4 [9] were initially used to identify $s t x_{2}$ and $s t x_{2 c}$, but have the same binding sites in the respective B-subunit genes as JS1 and JS2. Hae III and FokI were used to differentate between $s t x_{2}$ and $s t x_{2 c}$ as described previously [8]. SK1 and SK2 target the conserved region of eae and plasmid-specific sequences were detected with primers hlyA1 and hlyA4, wkat-B and wkat-F and D1 and D13R [9].

\section{Bacteriophage techniques}

Bacteriophage DNA was prepared by standard methods. For bacteriophage induction, a single colony of bacterial lysogen was grown in Trypticase Soy Broth (Oxoid) containing $5 \mathrm{mM} \mathrm{CaCl}_{2}$ to an $\mathrm{OD}_{600}$ of 0.5 . Then mitomycin $\mathrm{C}$ was added to a final concentration of $0.5 \mu \mathrm{g} / \mathrm{ml}$ and incubation was continued overnight in the dark. Cultures were centrifuged (15 min, $5000 \mathrm{~g}$ ) and supernates were filter-sterilised through membrane filters (Schleicher and Schüll, Dassel, Germany) of pore size $0.2 \mu \mathrm{m}$.

A double-layer agar method was used to investigate plaque formation. Plaque hybridisation was performed according to standard methods with the use of digoxigenin-11-dUTP labelling and detection kit (Boehringer GmbH; Mannheim, Germany).

\section{Standard DNA techniques}

Preparation and digestion of chromosomal DNA, labelling of gene probes and Southern blot hybridisation with $s t x_{1}$ and $s t x_{2}$ probes were performed as described previously [9]. Nucleotide sequencing was performed by Taq cycle sequencing with an automated sequencer (Model 377A, Applied Biosystems, Weiterstadt, Germany).

Nucleotide sequence analyses and searches for homologous DNA sequences in database libraries were performed with the programme package HUSAR (Heidelberg Unix Sequence Analysis Resources, German Cancer Research Center, Heidelberg, Germany) and the Lasergene software package (DnaStar, Madison, WI, USA).

\section{Results \\ Characterisation of E. coli isolates carrying multiple stx genes}

Multiple stx genes - $s t x_{1}, s t x_{2}$ and $s t x_{2 c}$ - were identified in three clinical isolates of $E$. coli. This was achieved with separate PCR reactions with primers KS7/KS8 and JS1/JS2, followed by restriction analysis of PCR products derived from primers JS1/JS2 with Hae III and FokI. Serotyping showed that the three strains belonged to serotypes O52:H19, O75: $\mathrm{H}^{-}$and $\mathrm{O} 157: \mathrm{H}^{-}$. The strains were designated 99, 4799 and 17069, respectively (Table 1). Culture filtrates of all strains were highly cytotoxic to Vero cells $\left(10^{3}-10^{5}\right.$ $50 \%$ cytotoxic doses $/ \mathrm{ml}$ of filtrate) (Table 1). In addition, all strains were subjected to colony-blot immunoassay with either the Stx1-specific monoclonal antibody (MAb) 13C4 or the Stx2-specific MAb IIEIO [14]. Both antibodies reacted with all three strains, indicating that the stx genes were expressed (Table 1).

Analysis of accessory virulence factors, as described for E. coli $\mathrm{O} 157$ [15], revealed that all three strains harboured eae gene and were positive for EHEC-hly genes. Whereas E. coli $\mathrm{O} 157: \mathrm{H}^{-}$strain 17069 possessed both the katP and espP genes, the nonO157 isolates were negative for both of these genes (Table 1).

Southern hybridisation of EcoR I-digested genomic DNA was performed with total DNA isolated from all three strains and control strains. With the $s t x_{1}$ probe, a single DNA fragment of $8.5 \mathrm{~kb}$ hybridised in tests with DNA from control strain C600 (H19J) (Table 1) and single fragments of $10.0,4.8$ and $7.2 \mathrm{~kb}$ hybridised with DNA from strains 99, 4799 and 17069, respectively (Table 1).

With the $s t x_{2}$ probe, hybridisation occurred with single DNA fragments of $4.8 \mathrm{~kb}$ and $5.8 \mathrm{~kb}$ from control strains C600 (933W) and E32511 (Table 1), respectively. Two hybridised fragments of different sizes were detected in tests with strains 17069 (5.5 and $7.5 \mathrm{~kb}$ ) and 99 (4.2 and $9.0 \mathrm{~kb}$ ) (Table 1). In the case of strain 4799 , four fragments of $4.5,7.0,8.2$ and $12.5 \mathrm{~kb}$ hybridised with the $s t x_{2}$ probe (Table 1).

\section{Plaque hybridisation}

The extent to which stx genes were associated with phages was investigated in induction experiments. Cultures of strains 17069, 99, 4799 and control strains C600 (H19J) and C600 (933W) were induced with 


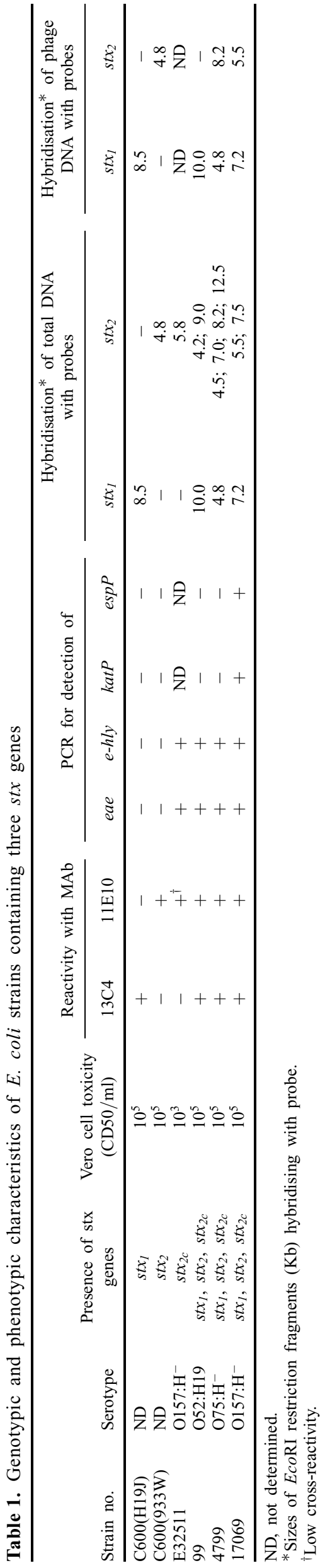

mitomycin C. Plaque formation on strain DH5 $\alpha$ was observed with phage lysates from both control strains and with strain 17069 of $\mathrm{O} 157: \mathrm{H}^{-}$, but not with lysates from the other two strains. Hybridisation analysis with $s t x_{1}$ and $s t x_{2}$ probes showed that $c .5 \%$ of the plaques formed by the phage lysate of strain 17069 hybridised with the $s t x_{1}$ probe, whereas the remaining $95 \%$ hybridised with the $s t x_{2}$ probe.

\section{Hybridisation of phage DNA}

Hybridisation of EcoRI-restricted phage DNA from strains 17069, 99 and 4799 was performed with stx and $s t x_{2}$ probes to determine whether the stx genes in the strains were located in the genome of prophages. DNA from phages H19J and $933 \mathrm{~W}$ was also hybridised. With the $s t x_{1}$ probe, a single DNA fragment $(8.5 \mathrm{~kb})$ of control phage H19J (Table 1) and of phage DNA prepared from strains $17069(7.2 \mathrm{~kb}), 99$ $(10.0 \mathrm{~kb})$ and $4799(4.8 \mathrm{~kb})$ hybridised, but no fragment from control phage $933 \mathrm{~W}$ (Table 1). With the $s t x_{2}$ probe, a single fragment of control phage $933 \mathrm{~W}$ $(4.8 \mathrm{~kb})$ and of phage DNA from strains 17069 $(5.5 \mathrm{~kb})$ and $4799(8.2 \mathrm{~kb})$ - but no fragment from control phage H19J or phage DNA from strain 99 hybridised (Table 1).

\section{Sequencing of stx genes}

Sequencing of $s t x_{1}$ PCR products of all three strains obtained with primers $\mathrm{KS} 7 / \mathrm{KS} 8$ and subsequent analysis yielded $100 \%$ identity with $s t x_{1}$. After amplification with primers JS1 and JS2, PCR products of all strains were cleaved with Hae III before analysis of $s t x_{2}$ sequences. The undigested fragment, when subjected to nucleotide sequence analysis, revealed $100 \%$ concordance with the $s t x_{2} B$ sequence reported by Schmitt et al. [3]. Characterisation of the $s t x_{2 c}$ sequence was performed on the undigested fragment after treatment of the PCR products with FokI. The $s_{2 c}$ sequence in the three strains investigated was $100 \%$ identical to the $s t x_{2 c} B$ sequences published by Schmitt et al. [3].

\section{Discussion}

Although STEC belonging to serogroups O52 and O75 have been isolated from patients with diarrhoea [16] and HUS [10], these strains belonged to serotypes different from those found in the present study namely O52:H25 [16] and O75:H5 [10] - and produced either Stx 2 or Stx 1 only. STEC of serogroups $\mathrm{O} 52$ and $\mathrm{O} 75$ have rarely been isolated from patients with HUS or diarrhoea in our laboratory in recent years. The fact that only three $(0.59 \%)$ of 507 STEC strains analysed in our laboratory between 1994 and 1997 possessed a combination of three different stx genes suggests that such strains are rare among clinical STEC isolates. This is consistent with the finding of Thomas et al. [7], who showed that isolates possessing a combination of $s t x_{1}, s t x_{2}$ and $s t x_{2 c}$ genes occurred with a low frequency in the $0157: \mathrm{H} 7 / \mathrm{H}^{-}$STEC group. 
Although Southern hybridisation of chromosomal DNA with the $s t x_{1}$ and $s t x_{2}$ probes showed the presence of $s t x_{1}$ and $s t x_{2} / s_{2} x_{2 c}$ genes in all three strains, only isolated phage DNA from strains 17069 and 4799 hybridised with the $s t x_{2}$ probe. This finding suggests that in strain 99 a Stx2-converting phage is not inducible by mitomycin $\mathrm{C}$ or that the $\operatorname{stx}_{2}$ gene in that strain is not phage-encoded. After mitomycin C induction, only strain 17069 formed plaques and these hybridised with $s t x_{1}$ and $s t x_{2}$ probes. Plaque formation was not observed with strains 99 and 4799. The simplest explanation for this phenomenon is that the indicator strains used in the plaque assay were not sensitive to these phages, because of a lack of specific receptors.

The extent to which multiple stx genes in one strain of STEC can modulate the level of virulence is not known and the specific role of each of Stx1, Stx 2 and Stx $2 \mathrm{c}$ in the pathogenesis of human disease has not yet been well defined. On the one hand, it is conceivable that strains possessing a combination of three different stx genes are more virulent than those harbouring only one, or two, stx genes - assuming that all three genes are expressed. On the other hand, the presence of three stx genes may be a biological disadvantage, in the sense that such strains are more susceptible to phageinducing agents in the intestine and this leads to the lysis of bacterial host cells. Consistent with the latter hypothesis is the fact that all three patients had uncomplicated diarrhoea.

The observations reported here suggest that Stx genotyping and phenotyping will become important for monitoring various STEC strains. Changes in toxin patterns can be monitored by the techniques described in this study. Characterisation of STEC strains expressing multiple stx genes will be an important topic for further investigations concerning virulence and epidemiology of STEC.

We thank Barbara Plaschke for excellent technical assistance. This work was supported by grant Ka 717/3-1 from the Deutsche Forschungsgemeinschaft.

\section{References}

1. Obrig TG, Del Vecchio PJ, Brown JE et al. Direct cytotoxic action of Shiga toxin on human vascular endothelial cells. Infect Immun 1988; 56: 2373-2378.

2. Louise CB, Obrig TG. Specific interaction of Escherichia coli
O157:H7-derived Shiga-like toxin II with human renal endothelial cells. J Infect Dis 1995; 172: 1397-1401.

3. Schmitt CK, McKee ML, O'Brien AD. Two copies of Shigalike toxin II-related genes common in enterohemorrhagic Escherichia coli strains are responsible for the antigenic heterogeneity of the $\mathrm{O} 157: \mathrm{H}^{-}$strain E32511. Infect Immun 1991; 59: 1065-1073.

4. Brien AD, Newland JW, Miller SF, Holmes RK, Smith HW, Formal SB. Shiga-like toxin-converting phages from Escherichia coli strains that cause hemorrhagic colitis or infantile diarrhea. Science 1984; 226: 694-696.

5. Scotland SM, Smith HR, Willshaw GA, Rowe B. Vero cytotoxin production in strain of Escherichia coli is determined by genes carried on bacteriophage. Lancet 1983; 2: 216-216.

6. Johnson RP, Clarke RC, Wilson JB et al. Growing concerns and recent outbreaks involving non-O157:H7 serotypes of verotoxigenic Escherichia coli. J Food Prot 1996; 59: $1112-1122$.

7. Thomas A, Smith HR, Rowe B. Use of digoxigenin-labelled oligonucleotide DNA probes for VT2 and VT2 human variant genes to differentiate Vero cytotoxin-producing Escherichia coli strains of serogroup O157. J Clin Microbiol 1993; 31: $1700-1703$.

8. Rüssmann H, Schmidt H, Heesemann J, Caprioli A, Karch H. Variants of Shiga-like toxin II constitute a major toxin component in Escherichia coli O157 strains from patients with haemolytic uraemic syndrome. J Med Microbiol 1994; 40: 338-343.

9. Schmidt H, Geitz C, Tarr PI, Frosch M, Karch H. NonO157:H7 pathogenic Shiga toxin-producing Escherichia coli: phenotypic and genetic profiling of virulence traits and evidence for clonality. J Infect Dis 1999; 179: 115-123.

10. Bockemühl J, Aleksic S, Karch H. Serological and biochemical properties of Shiga-like toxin (verocytotoxin)-producing strains of Escherichia coli, other than O-group 157, from patients in Germany. Int J Med Microbiol Virol Parasitol Infect Dis 1992; 276: $189-195$.

11. O'Brien AD, Lively TA, Chen ME, Rothman SW, Formal SB. Escherichia coli O157:H7 strains associated with haemorrhagic colitis in the United States produce a Shigella dysenteriae 1 (SHIGA) like cytotoxin. Lancet 1983 1: 702.

12. Strockbine NA, Marques LRM, Newland JW, Smith HW, Holmes RK, O'Brien AD. Two toxin-converting phages from Escherichia coli O157:H7 strain 933 encode antigenically distinct toxins with similar biologic activities. Infect Immun 1986; 53: $135-140$.

13. Strockbine NA, Marques LRM, Holmes RK, O’Brien AD. Characterization of monoclonal antibodies against Shiga-like toxin from Escherichia coli. Infect Immun 1985; 50: 695-700.

14. Perera LP, Marques LRM, O'Brien AD. Isolation and characterization of monoclonal antibodies to Shiga-like toxin II of enterohemorrhagic Escherichia coli and use of the monoclonal antibodies in a colony enzyme-linked immunosorbent assay. J Clin Microbiol 1988; 26: 2127-2131.

15. Karch H, Schmidt H, Brunder W. Plasmid-encoded determinants of Escherichia coli O157:H7. In: Kaper JB, O'Brien AD (eds) Escherichia coli O157:H7 and other Shiga toxinproducing E. coli strains. Washington, DC, American Society for Microbiology. 1998: 183-194.

16. Bettelheim KA, Brown JE, Lolekha S, Echeverria P. Serotypes of Escherichia coli that hybridized with DNA probes for genes encoding Shiga-like toxin I, Shiga-like toxin II, and serogroup O157 enterhemorrhagic $E$. coli fimbriae isolated from adults with diarrhea in Thailand. $J$ Clin Microbiol 1990; 28: $293-295$. 